\title{
Blockchain for Waste Management in Smart Cities: A Survey
}

\author{
Raja Wasim Ahmad, Khaled Salah, Raja Jayaraman, Ibrar Yaqoob, Mohammed Omar
}

\begin{abstract}
Smart cities have the potential to overcome environmental problems caused by improper waste disposal to improve human health, protect the aquatic ecosystem, and reduce air pollution. However, today's systems, approaches, and technologies leveraged for waste management are manual and centralized that make them vulnerable to manipulation and the single point of failure problem. Also, a large portion of the existing waste management systems within smart cities fall short in providing operational transparency, traceability, audit, security, and trusted data provenance features. In this paper, we explore the key role of blockchain technology in managing waste within smart cities as it can offer traceability, immutability, transparency, and audit features in a decentralized, trusted, and secure manner. We discuss the opportunities brought about by blockchain technology in various waste management use cases and application scenarios, including real-time tracing and tracking of waste, reliable channelization and compliance with waste treatment laws, efficient waste resources management, protection of waste management documentation, and fleet management. We introduce a framework that leverages blockchain-based smart contracts to automate the key services in terms of waste management of smart cities. We compare the existing blockchain-based waste management solutions based on important parameters. Furthermore, we present insightful discussions on several ongoing blockchain-based research projects and case studies to highlight the practicability of blockchain in waste management. Finally, we present open challenges that act as future research directions.
\end{abstract}

Index Terms-Blockchain; Waste management; Traceability; Security; IoT; Smart Cities

\section{INTRODUCTION}

Since the past decade, worldwide cities have been continuously generating an enormous amount of waste that is putting a harmful effect on human health and the environment. It is estimated that the world generates up to 1.3 billion tonnes of solid waste each year and it is expected to increase to 2.2 billion tonnes per year by 2025 . On average, every human being generates around 0.11 to 4.54 kilograms of solid waste per day. It is reported that $33 \%$ of the generated solid waste in cities do not manage in an environmentally friendly and safer way $[1,2]$. The improper management of waste can contaminate the oceans, cause diseases spreading, and harm animals that eat waste (e.g., food waste or plastic bags) unknowingly. The proper management of waste in smart cities require close coordination and collaboration among the involved

R. W. Ahmad, K. Salah, and I. Yaqoob are associated with Department of Electrical Engineering and Computer Science, Khalifa University of Science and Technology, Abu Dhabi 127788, UAE.

R. Jayaraman and M. Omar are associated with Department of Industrial \& Systems Engineering, Khalifa University of Science and Technology, Abu Dhabi 127788, UAE.

Corresponding author: Ibrar Yaqoob (ibraryaqoob@ieee.org) stakeholders such as waste generators, collectors, shipper, and waste treatment facilities. However, the existing systems leveraged to manage waste are highly disintegrated and face several challenges because of a lack of means to adequately share waste-related data among involved stakeholders in waste management processes [3-5]. Blockchain technology presents a single and unified platform that can be used by the involved stakeholders in waste management of cities to share data in an effective, secure, transparent, and verifiable manner [6-8]. Since blockchain follows decentralized architecture, hence it is a highly fault-tolerant, robust, and trusted technology.

Modern cities face manifold challenges related to air pollution, deteriorating and inappropriate water management, sustainable and eco-friendly energy creation, and environmentally friendly waste management. Smart cities aim to improve citizens' quality of life, protect the environment, minimize traffic congestion, and increase the local economy by leveraging state-of-the-art Information Communication Technologies (ICT) [9, 10]. Effective and sustainable waste management policies assist in improving air and water quality and lessening carbon emissions to clean the environment. Many of the waste management systems are highly Internet of Things (IoT)-based and leverages centralized cloud-based resources to process the waste-related data. IoT-based nodes sense, monitor, and transmit the capacity and type of waste in bins, temperature, and humidity level, and estimated arrival time and route data about the waste carrying trucks to the cloud servers for processing and decision making [3, 4, 11]. For instance, the smart bins capacity data can be used to forecast the availability of the vehicles near the waste bin site [12]. The centralized data storage and processing often result in data inconsistency among the involved waste handling participants, thereby offering limited collaboration opportunities to the stakeholders. Also, the data stored on a centralized-based system is less trustworthy as it is highly vulnerable to modifications, fraud, or deletion by intruders.

Blockchain is a decentralized technology that can assist in securing data and transactions by storing and executing them in a trustful manner. It follows a Peer-to-Peer (P2P) architecture to store and process data in a highly reliable, secure, transparent, and trusted way $[13,14]$. Blockchain technology allows and provides incentives to the miners to participate in the consensus process to validate the transactions and create new blocks. Consensus algorithms secure the blockchain by ensuring that unverified transactions cannot be executed and stored on the blockchain [15]. Since blockchain platforms follow a distributed architecture, the consensus algorithms such as Proof-of-Work (PoW) [16], Proof-of-Stake (PoS) [17], 
and Proof-of-Authority (PoA) [18] are obliged to ensure the agreement to the current state of the blockchain among all distributed nodes. Broadly, existing blockchain platforms are categorized as permissionless and permissioned. Permissionless blockchain platforms are public and allow users full access to the transactions stored on the ledger. Permissioned blockchain platforms are usually private and controlled by a designated organization. It offers access to a limited number of organizations to assure that data privacy and security are preserved [19]. Ethereum [20] is a decentralized and open-source permissionless blockchain platform that allows digitizing and tracking the assets through smart contracts. Nevertheless, Quorum [21] that basis on the Ethereum platform is classified as a permissioned platform. Similarly, Hyperledger Fabric [22] falls under the permissioned platform category as it allows the stakeholders to communicate in a private manner.

Smart contracts represent programs stored on the blockchain with terms of the agreement between participants of waste management processes. They automatically execute and trigger events after meeting predetermined criteria in the agreement. Also, they assist the stakeholders in performing business operations in a faster, cheaper, and secure way compared to traditional systems that require intermediaries to commit the business operations. Based on characteristics and lifetime of smart contracts, they are of several types such as dormant, active, prolific, self-destructed, and active. The existing studies that have employed smart contracts to automate the smart cities services have mainly considered smart grids, smart healthcare, smart homes, smart transportation, supply chain management, smart industries, and agriculture [23-27].

To the best of our knowledge, none of the existing studies have explored or reviewed the opportunities offered by blockchain in terms of waste management of smart cities. We conduct this study to explore the role of blockchain in waste management, present several blockchain-based research projects and case studies, and discuss the challenges that need further research to improve waste management services in smart cities. The key contributions of this paper are as follows:

- We review the key opportunities brought about by blockchain technology for waste management of smart cities to improve operational transparency, traceability, security, and accountability in waste management processes.

- We present a blockchain-based framework for waste management services and compare existing state-of-theart blockchain-based waste management solutions based on important parameters.

- We report several blockchain-based research projects and case studies to demonstrate the practicality of blockchain technology in waste management of smart cities.

- We identify and discuss several open research challenges hindering the successful implementation of blockchain technology in terms of waste management within smart cities.

The rest of the paper is organized as follows. Section II presents the opportunities offered by blockchain technology in terms of waste management in smart cities. Additionally, it presents a tabular comparison of existing blockchain-based studies related to waste management. Section III discusses recent blockchain-based projects and case studies related to waste management in smart cities. Section IV presents a discussion on research challenges in the waste management field. Section V provides concluding remarks.

\section{OPPORTUNITIES FOR BLOCKCHAIN IN WASTE MANAGEMENT OF SMART CITIES}

The rapid worldwide expansion of cities causes several environmental and social challenges. The increased rate of urbanization, economic development, world population growth, and the rise in the standard of living in developing counties are major causes of the amount, rate, and variety of generated waste [28, 29]. Figure 1 highlights the key opportunities offered by blockchain technology to enforce trust among participating organizations involved in the waste management of smart cities. Further discussion is provided in the following subsections.

\section{A. Tracing and Tracking of Waste of Smart Cities}

Smart cities generate domestic, commercial, medical, agricultural, and industrial waste. Such waste is often sent to landfills, waste recycling facilities, composters, and waste to energy generation plants. Tracing and tracking features can be useful to verify the authenticity of data and ethical practices involved in the collection, processing, and shipment of smart cities waste [30-33]. These features assist in monitoring the current location and state of the waste during their collection, segregation, shipment, treatment, and disposal or recycling. The traceability feature is valuable since it assists in identifying, storing, and managing detailed data about the activities and outcomes during waste management processes. The most important data which is recorded during waste management includes waste type, volume, shipping location and route, transit time status, and details about the waste handler and their actions in each waste management stage. Examples of smart cities' waste include liquid or solid household waste, medical waste, hazardous waste, recyclable waste, green waste, and electrical waste (E-waste). Today's centralized systems that are often employed to manage waste-related data are vulnerable to modification and alteration by the planned or accidental damages [34].

The traceability feature assures that the waste generated by smart cities is handled in compliance with the waste handling guidelines to protect the environment from pollution. It also enables users to efficiently track the end of life of the smart cities waste [35]. For instance, blockchain can be used to identify the type of healthcare waste that is processed at a waste recycling facility and is used in manufacturing medical equipment and devices. The industries can employ blockchain technology to identify which and from where leftovers and food waste are shipped to a waste recycling plant to make fertilizer. Based on such data, a new fertilizer production line can be established near the waste source to reduce the waste transportation cost. The tracking feature of blockchain technology enables users to record the current location of 


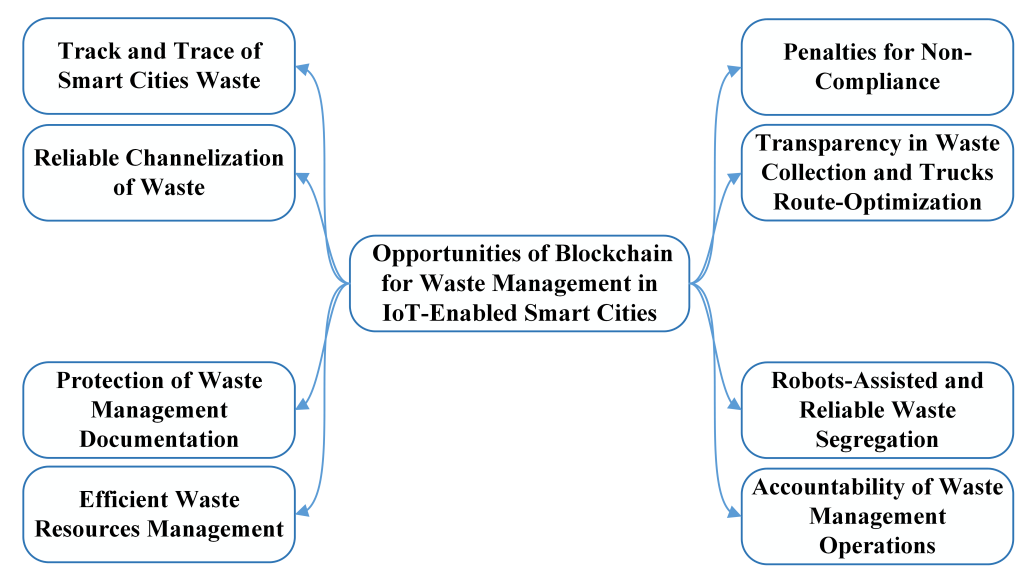

Fig. 1. An overview of the key opportunities offered by blockchain in terms of waste management in smart cities.

trucks shipping smart cities waste along with other data such as shortest route and waste weight. Such data related to the waste shipping location can be used to verify that the wastecarrying truck has traveled through certain stations before reaching the final destination. Waste is usually transported from different locations and communities, the blockchain can assist assuring using sensors attached to waste bags that hazardous waste does not get mixed with nonhazardous waste during its transportation for human safety assurance. Lastly, due to transparency and immutability features, blockchain can be used to track the amount of waste shipped, received, and recycled at the recycling plant, credentials of the waste handler and their actions, and storage location of waste when it is segregated, sorted, and recycled or disposed of. Based on the immutable record of data and transactions, the blockchain can verify and identify any missing waste by comparing the weight of received and shipped waste. Figure 2 highlights a blockchain-based system in which the smart city users store and retrieve waste management-related data using deployed smart contracts. The presented system allows citizens to view the current location and route trajectory of their generated waste.

\section{B. Reliable Channelization of Waste}

The life period and reliability of many electronic devices are different, and it truly depends on electronic devices' composition, working environment, temperature, and required voltage supply level to operate it. After the expiry of such electronic devices, they should be recycled or disposed of responsibly at authorized E-waste recycling plants. For instance, many smartphone devices contain expensive lithium and cobalt materials that could be reused after smartphone expiry to manufacture new products [30]. Therefore, reliably channelizing the E-waste can lead to a pollution-free smart city. The producers of the electronic devices (e.g., smart TVs, refrigerators, and smartphones) are usually required to monitor such electronic devices after their expiry [36, 37]. They can assure that E-waste of all sold electronic devices is collected at the waste treatment centers. Through the lifetime of each electronic device and total supply in the market, blockchain technology can assist to assure that E-waste of all sold-out electronic devices is collected at the waste treatment centers. The producers can collect the E-waste using registered retailers, designated collection centers, or authorized dismantlers/recyclers. Through reward and penalty smart contracts, it can be assured that the retailers and collection centers should ship the E-waste to the producer within a threshold period to keep the city clean and safe.

Smart cities' users can use blockchain to channelize their domestic, medical, agricultural, and electronic waste, and incentives are issued to them on selling this waste. The auditable, immutable, and transparent features of blockchain technology can increase the trust of smart city users in monetizing their waste to channelize it. Smart contracts can be developed and deployed on blockchain to enforce customers to transfer an escrow amount into a smart contract wallet on purchasing a product. This escrow amount will be automatically released to the wallet of the consumer on returning the waste of purchased product after their usage [10, 38, 39]. Hence, through blockchain-based data, it can be ensured that the waste of all products has been collected successfully. Usually, citizens are charged a flat service fee to ship their waste to sell it at a retailer or waste treatment facility. A smart contract calculating and automatically transferring cryptocurrency in a consumer's wallet based on the weight of the waste can motivate citizens to produce less waste. Blockchain in such a scenario can be used to settle payment-related issues, and it can identify the waste-related frauds [40]. Also, in another case study related to smart agriculture, the farmers can sell crop straws and animal residue to a company generating electricity from the waste. As a reward, users/farmers are provided with coupons against the provided waste in compliance with the rules stated in a smart contract [41, 42]. These coupons can be used to pay their monthly electricity bills. Also, through smart contracts, blockchain technology can automatically calculate the wages to be paid to the participants involved in waste segregation.

\section{Protection of Waste Management Documentation}

Today's centralized systems leveraged for managing waste management within smart cities are less trustworthy as they 


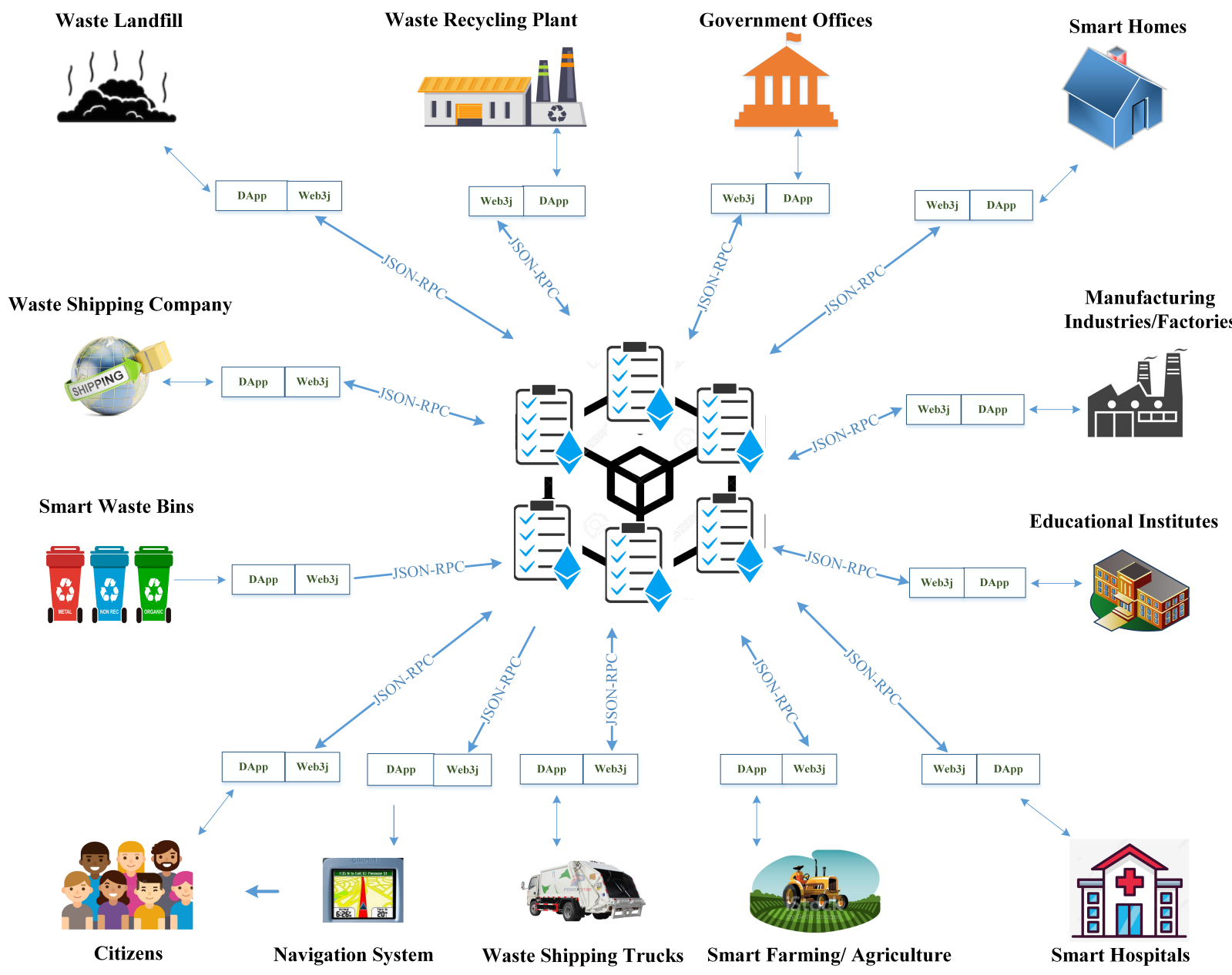

Fig. 2. An overview of waste-related data storing and retrieving using the blockchain-based system.

offer limited transparency features. As a result, it is difficult to verify that waste management practices adopted by an industry such as healthcare are complying with rules proposed by regularities for the safety of humans and the environment. The waste management-related certificates and documents state the rules, methods, and procedures to be followed during the collection, transportation, segregation, and recycling of waste. The key documents and certificates that are maintained by the waste handling organizations during waste management include waste disposal recycling form, waste declaration form, dangerous goods shipping document (e.g., asbestos or flammable liquids), waste management inspection plan document, and waste manifest form, to name a few [4345]. The certificates of an individual or organization such as license documents are issued by the authorities to assure safe and environmentally friendly waste management. All waste management-related documents and forms are duly signed by the authorized and relevant organizations before processing the waste, and they can be used as proof to resolve the conflicts among organizations. Since these documents and certificates are managed manually or using centralized systems, hence they are subject to any accidental loss, damage, manipulation, and modification performed by hackers.

Blockchain technology can be used to minimize frauds related to documents (e.g., scraps metal dealers licenses) maintained during waste handling within a city. It employs self-executing smart contracts and irreversible hash functions to speed up the waste management process, protect the documents from manipulation, and data inconsistency. The documents related to waste management should be encrypted and stored on InterPlanetary File System (IPFS) [46, 47] to efficiently utilized blockchain storage capacity. The hashes of such documents should be securely shared among the participating organizations through a blockchain platform. Any alteration to the waste management documents stored on the IPFS can be identified using the stored on-chain IPFS hash of the document. Hence, the participating organizations can quickly verify the authenticity of documents related to waste management and the licenses of the participants involved in the waste management activities. The consensus protocols that are proposed to commit the waste management transactions and immutable data provenance make forging of license or waste management documents forging theoretically impossible.

\section{Efficient Waste Resources Management}

The IoT-based systems enable remote monitoring and assist in controlling smart cities through a network of deployed sensors to collect real-time data and getting insights from such 


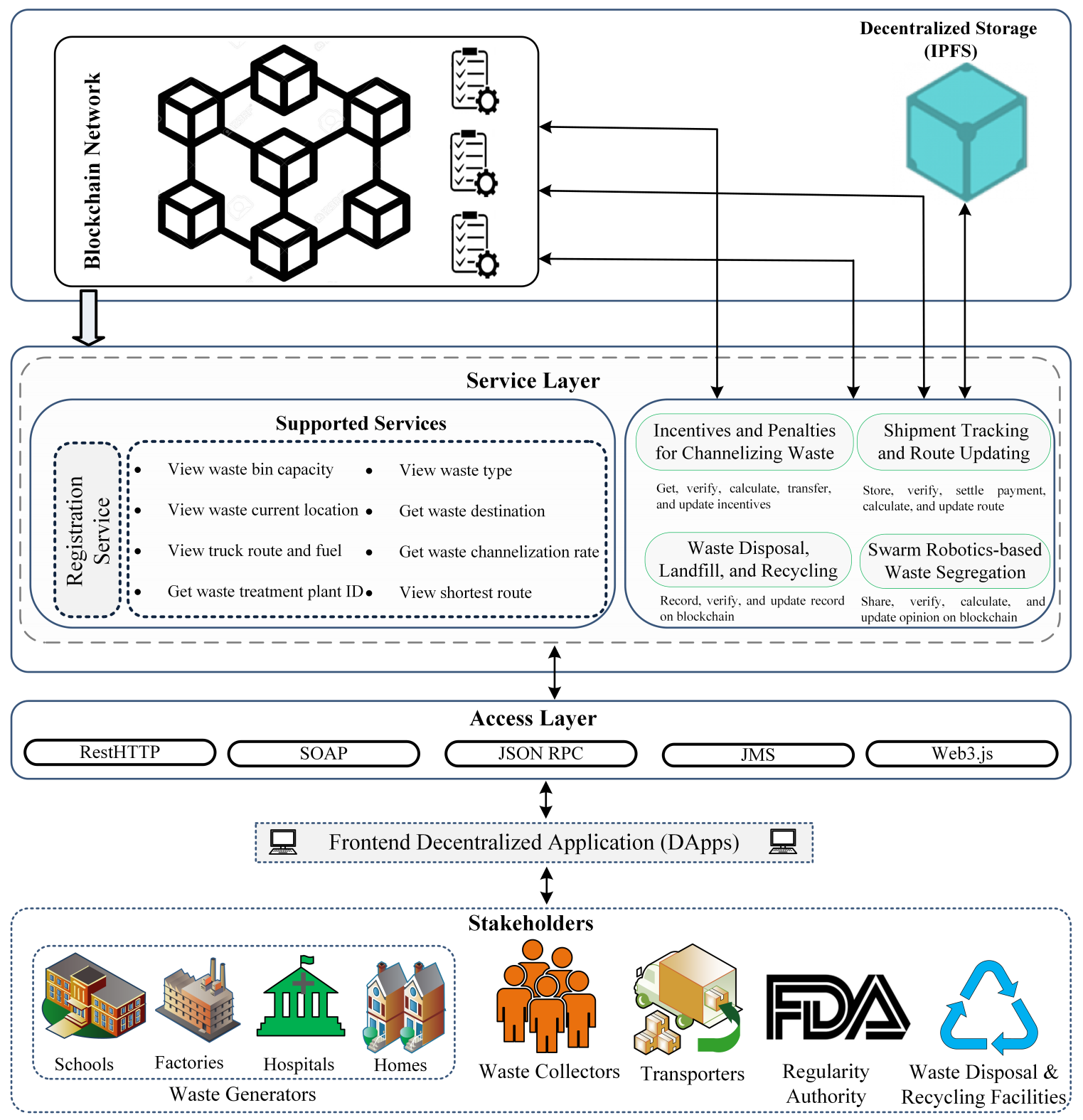

Fig. 3. Blockchain-based framework for waste management services in smart cities.

data. Based on such data, plans and actions can be made to reduce congestion and traffic interruption, disease transmission, carbon dioxide emission, and make the environment cleaner and safer by timely collecting and processing smart cities waste $[48,49]$. Through the analysis of smart city data, the idle resources in a city can be identified and optimally used. The key resources used in waste management of the smart cities include waste bins, transportation trucks, Waste management workers, waste segregation or dumping location, waste-toenergy facility, disposal sites, and residential waste places. These resources are required to be efficiently handled to minimize the waste management cost and improve well being of citizens. The lack of transparency to the waste management resources and activities in existing centralized-based systems can lead to less trustworthy, inefficient, non-fault tolerant, and insecure systems. Thus, the resource management decisions on the basis of potentially untrusted and modifiable data can be inefficient and costly.

Data immutability and fault tolerance features make blockchain a favorite technology for authorities to efficiently and quickly manage resources in smart cities. Blockchain can register all the entities along with their role, and smart cities resources using a registration smart contract. Authorities can use the deployed audit smart contract to identify that how many waste management resources are underutilized in a particular area of a smart city since last month. Usually, RFID sensors are attached to the waste management resources such as smart bins to periodically monitor and store data about their available storage capacity on the blockchain. Through the analysis of blockchain-based waste management-related data, it can be estimated that how frequently the waste bins request the transporters to move the collected waste to the waste treatment/disposal facility. Authorities can estimate the volume of waste being transported from a particular area of 
the smart city using analysis of such data. Based on this waste data, authorities can shift the underutilized waste management resources to the needed areas for efficient utilization of existing resources. Also, the trusted waste data acts as a business opportunity to establish the waste treatment plants near the waste source. On identifying the type of waste in the collected food waste, the food industry can be strengthened by opening new restaurants in smart cities based on the food requirement of the citizens. Figure 3 presents a blockchain-based system that can be used to digitize the services of waste management in smart cities. The presented system has shown a set of services that can be implemented through smart contracts. For instance, based on the location data and capacity of the waste bins, the drivers can be notified about the shortest and fuelfriendly path to collect the waste in a smart city. A system presented in figure 4 highlights the interaction between waste collectors and waste recycling centers. It assures that waste collectors have received their funds on selling their collected waste to the waste recycling center.

\section{E. Penalties for Non-compliance}

According to the waste management act 2016, the waste generators within a community are responsible to segregate and store the waste in appropriate bins, and handover it to the waste handling workers to dispose of it at the registered waste treatment facilities. In the design of IoT-enabled smart cities, all types of waste such as biodegradable and non-biodegradable, domestic hazardous, and industrial wastes should be stored in separate waste bins classified by different colors. The volume of the waste generated by smart cities industries depends on their size, type of services, and production level. Hence, based on the volume and type of waste generated by industries in smart cities, they are required to be registered under hazardous waste producers on producing more than 500 kilogram of hazardous waste in a year [36, 50]. Also, waste treatment processes of the waste treatment plants should be covered under certain environmental permits to protect the environment from the effects of harmful carbon emissions. Individuals, organizations, and industries are imposed heavy fines or penalties such as license cancellation on any noncompliance with the approved waste management practices.

The architectural decentralization, traceability through the timestamped transactions, and use of consensus protocols make blockchain a fault tolerance technology that drives the authorities to use it for assurance of compliance of actions with approved waste management rules. Further, it assists in automating the imposing of fines and issuing penalties on identifying any non-compliance with the approved rules in a transparent and audit-able way. For instance, during the pandemic caused by the COVID-19 outbreak, it was declared by the World Health Organization (WHO) that the users in COVID-19 hospitals or testing centers should carefully collect and store COVID-19 related waste to minimize the virus from spreading. Also, the bags carrying the COVID-19 related waste should be sealed properly to assure that they are not exposed by the handlers during their shipment. Blockchain, in this case, can assist in monitoring the shipment and issue penalties to the waste handlers on identifying any non-compliance with waste transportation rules [34, 51]. It is desired that the COVID19 waste should be transported by licensed users. Blockchain can assist the authorities to verify the license of a shipper through the immutable record of transactions and data, and issue heavy fines on identifying any non-compliance with the rules. Minimizing the food waste in smart cities is another challenge for the authorities to protect the citizens from disease and infection. Blockchain can play a role in identifying and issuing penalties to an individual/industry involved in food waste. For this purpose, a smart contract can verify the type of waste generated by a community, and it issues fines on encountering a non-compliance with the food waste-related rules. For instance, it can impose penalties on citizens on identifying that the average food waste per day is above a pre-defined threshold limit.

\section{F. Transparency in Waste Collection and Trucks Route Opti- mization}

In smart cities, the IoT-enabled smart waste bins that are capable of monitoring the waste state inside the bins and transmitting real-time data to the central storage servers through wireless links are deployed [52]. The sensors attached to the smart bins can measure waste level, humidity, temperature, weight, and type of waste inside the bins. Data collected by such sensors about the waste can assist to predict the bins fill level, identify potential diseases in a community based on the type of collected waste, and forecast the volume of waste that will be collected in near future based on the current waste generation rate by a community. The waste collection involves several stakeholders such as municipality workers, waste shipment trucks, waste sources, and environment protecting agencies. Waste collection in smart cities is a daily activity that involves truck route planning and optimization while considering environmental and socioeconomic factors. The routes planning for collecting smart cities waste is affected by several parameters such as traffic jams, fuel costs, amount of waste collected per route, and the number of trucks available along with their capacity [39, 53, 54]. The route planning on the basis of a centralized-based system can be ineffective or costly since data can be compromised or tampered with. Also, the existing systems offer limited transparency to the waste management data, which can affect the truck's route optimizations.

Blockchain technology can assist in tracking the amount of waste collected, the details about who collected it, the location from where this waste is collected, and the current and final location of the waste. Through the data stored on the blockchain by the sensors, a route and schedule to pick up the waste can be formulated to minimize the fuel consumption rate of the trucks and maximize the amount of waste collection per route. The high visibility and transparency to the waste collection activities and sensor data can enable the authorities to assure that the filled waste bins are picked up timely by legitimate users. The smart contracts can trigger a notification to the truck drivers on identifying that the storage capacity of the waste bin has reached an unsafe threshold value. Also, other than 
the sensors located inside the bins, external sensors attached to the bins can continuously monitor their surroundings. Thus, through such sensors and rotatable cameras attached to the bins, any illegal dumping near the waste bin is identified and recorded on the blockchain along with the identifier of the individual who caused it. On encountering any such incident, the smart contracts can notify the authorities about such users for any legal actions. Further, an analysis of trusted healthcare waste data and food waste collected through trucks can enable authorities to identify common community diseases. Figure 5 discusses the activities of stakeholders involved in waste to energy transformation processes. As highlighted in figure 5, the farmers are rewarded with tokens for disposing of their waste properly. Such tokens can be used to purchase food, pay utility bills, and exchange them into cash money.

\section{G. Robots-Assisted and Reliable Waste Segregation}

Industrial and smart home waste such as paper and glass is recyclable. Therefore, recycling of such materials can increase their circular economy. The industrial and smart home waste in smart cities can be classified as hazardous waste, liquid waste, solid non-hazardous waste, and bio-degradable wastes. Among all aforementioned waste types, liquid waste includes wash water, organic liquid, waste detergents, and dirty water $[55,56]$. The segregation process aims at identifying the recyclable materials from the waste to protect the ecosystem, save energy, reduce carbon emissions, and conserve natural resources. The older systems involved humans segregating the waste in the hazardous environment that, as a result, can affect their health. Modern waste management methods have started practicing robots to segregate the waste, thus minimizing the human interaction with hazardous waste [5759]. The automated robots-based waste segregation system highly depends on image processing techniques for object recognition and Artificial algorithms (AI) algorithms to accurately classify the waste based on their type, color, or shape [60]. However, the existing robots-based waste segregation systems are less trustworthy because of the following of the centralized architectures.

A swarm consists of a network of heterogeneous robots that work together to perform the required task or actions. In the waste segregation process, a swarm of robots can automatically identify the recyclable materials from the waste by communicating with each other and sharing their opinion about the type of waste under consideration. Each robot is AI-enabled, thus it is capable of interacting with others by following a predefined set of rules. Blockchain technology enables robots to securely communicate with each other in a trusted way. Through this technology, swarm operations are autonomous, flexible, and even profitable. The information shared by the robots in a swarm is trustworthy for others since the sender uses its digital signature to sign it. Also, through a blockchain-assisted voting-based system [47, 61], the swarm can decide about a particular item in the waste based on a set of parameters such as shape, color, and texture. The rules defined in the smart contracts can calculate the sum of the opinions of the robots and declares the opinion of the majority as the final decision. Blockchain can minimize the waste segregation time, improves waste handling efficiency, and present an audit-able way to issue incentives to the owners of the robots involved in the waste segregation process.

\section{H. Accountability of Waste Management Operations}

The waste in smart cities produced by the hospitals, smart industries, homes, and smart grid systems is often collected and managed by private companies, community owners, or designated representatives of the state. The waste management strategies such as recycling, recovery, prevention, and reuse involve diverse stakeholders effectively and sustainably utilizing waste management-related resources such as waste landfill [56, 62]. The involved stakeholders in the waste management process identify waste material to be recycled using their RFID tags [63]. The actions of the stakeholders involved in managing waste in smart cities should comply with the waste management laws to govern the storage, treatment, shipment, recycling, and disposal of all types of waste. The existing systems responsible to manage waste in smart cities are inefficient in holding individuals or organizations accountable for their services that have caused a delay or loss of waste at any stage. Through blockchain technology, the involved stakeholders such as producer, shipper, consumer, and waste handler can be placed into a single network of connected nodes, thus, making data and transactions visible and transparent to the authorized parties.

There are many use case scenarios that require accountability of the user's actions involved in waste management to assure compliance with rules for a cleaner and safer city. Through blockchain, the authorities can verify that the hazardous industrial waste is unloaded at the designated recycling location. It can further assist in verifying the lost waste by comparing the volume of shipped and received waste at the disposal center, establish provenance data about the household waste, calculate and present the percentage of incinerated and disposed of waste, and verify the recycling capability of a plant and the actual waste recycled for plannings, based on the analysis of the waste-related data stored on blockchain [64]. Through transaction transparency and data traceability features, it can identify the impossible fast transportation and unnecessary fuel consumption during waste shipment. It can also assist the authorities to trace the waste shipped to illegal dumping sites to avoid waste landfill taxes. Finally, the blockchain can identify that the industrial water in a particular industry has been given Wastewater treatment or not [65].

Table I compares the existing blockchain-based solutions related to waste management. The solutions mainly focus on waste shipment tracking, waste-related fraud identification, transparent waste sorting, and accountability of stakeholder's actions. They are based on highly proficient models to motivate the citizens to channelize their waste by issuing rewards and penalties. Also, some of the existing studies focus on electronic, general, solid, agricultural, and industrial waste to provide incentives to citizens to channelize their waste. 


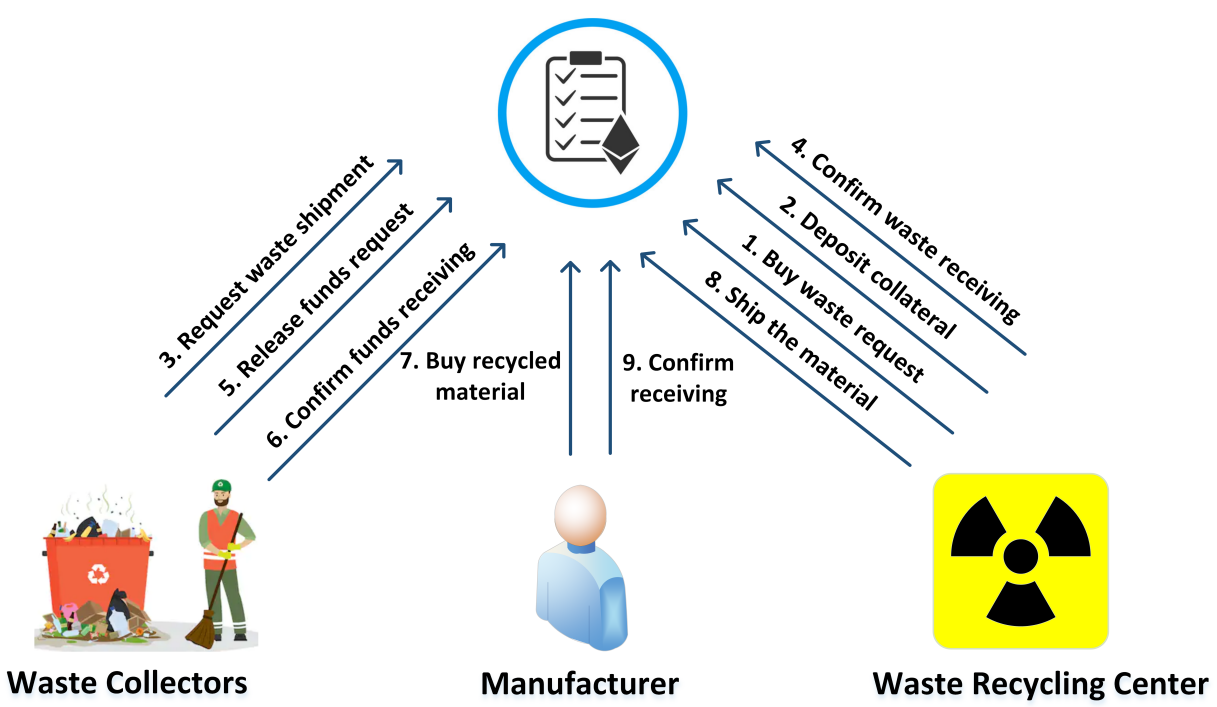

Fig. 4. Interaction between waste collectors and the waste recycling center using a blockchain-based smart contract.

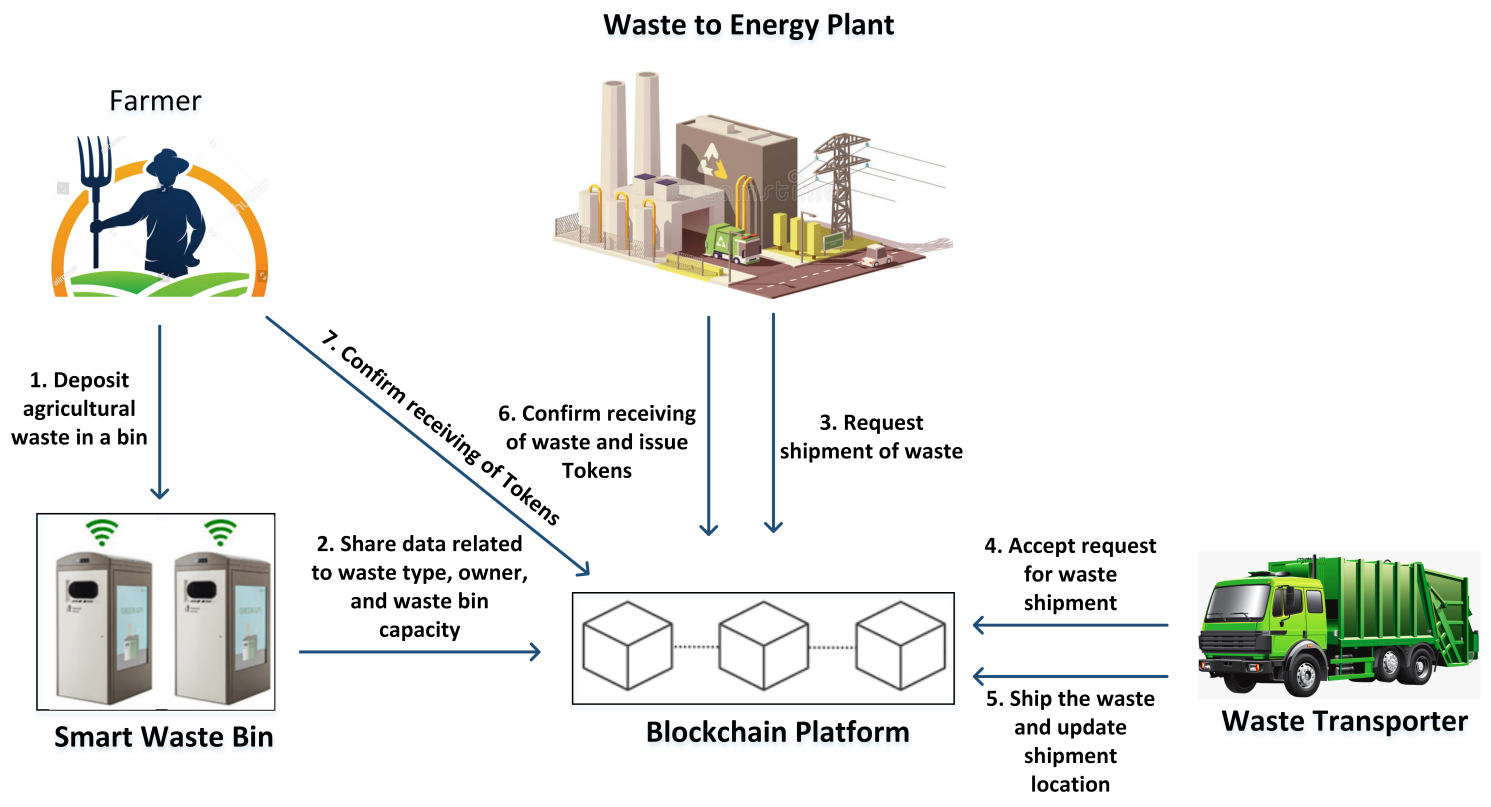

Fig. 5. Highlighting the actions of stakeholders using a blockchain-based system to generate energy from the agricultural waste.

\section{Research Projects And Case Studies}

This section presents insightful discussions on the recent blockchain-based projects and case studies that mainly focus on digitizing waste management operations within smart cities.

\section{A. Recerreum}

Recently, many countries have formulated legislation about domestic waste management in urban areas. Many governments have proposed monetary incentives or punishments to motivate citizens to channelize their domestic waste, thereby increasing the waste recycling rate. The main barriers to the success of existing centralized-based waste management include waste-related information modification, technological externalities, high search and transaction costs due to highly disintegrated waste channelization centers, and consumer perceptions about the waste management responsibilities. Recerreum (RCM) is an Ethereum based framework that gives monetary benefits to the citizens as a reward to sort the domestic waste at waste source [68]. It aims that the citizens should be able to make money from every recycled bottle, battery, bottle, or piece of electronic equipment in a transparent and effective manner. The RCM coins can be deposited in the wallet of the citizens on depositing waste at a designated center such as bottles vending machine, stations collecting recyclables, and waste collections centers. These coins can be used by the citizens for making payments against their electricity bills or any other services. The blockchain in RCM has many applications such as smart contracts based verification of the waste deposited, fast and automated payment settlement, and 
TABLE I

COMPARISON OF THE EXISTING BLOCKCHAIN-BASED SOLUTIONS PROPOSED FOR WASTE MANAGEMENT IN SMART CITIES.

\begin{tabular}{|c|c|c|c|c|}
\hline Article & Waste Type & Objectives & Services & Rewards/Penalties \\
\hline [10] & Electronic Waste & $\begin{array}{l}\text { To efficiently manage electronic waste using an Ethereum blockchain } \\
\text { platform in 5G- enabled environment }\end{array}$ & Asset Tracking & Rewards \\
\hline [38] & Electronic Waste & $\begin{array}{l}\text { To investigate the role of blockchain for waste handling in compliance } \\
\text { with rules stated in waste management act }\end{array}$ & $\begin{array}{l}\text { Waste Shipment Tracking, } \\
\text { Auditability }\end{array}$ & Both \\
\hline [64] & General Waste & $\begin{array}{l}\text { To track and monitor the flow of waste across the borders in a way that } \\
\text { is transparent }\end{array}$ & $\begin{array}{l}\text { Waste Shipment Tracking, } \\
\text { Auditability }\end{array}$ & N/A \\
\hline [66] & General Waste & $\begin{array}{l}\text { To connect all participants and track the waste by assuring waste data } \\
\text { reporting on a single platform }\end{array}$ & $\begin{array}{l}\text { Waste Tracking, } \\
\text { Auditability }\end{array}$ & N/A \\
\hline [34] & Medical Waste & To assure that medical waste is handled in compliance with safety rules & $\begin{array}{l}\text { Waste Shipment Tracking, } \\
\text { Auditability, } \\
\text { Transparency }\end{array}$ & Penalties \\
\hline [67] & Solid Waste & $\begin{array}{l}\text { Employing a blockchain-based system for life cycle assessment of solid } \\
\text { materials }\end{array}$ & $\begin{array}{l}\text { Waste Tracking, } \\
\text { Policy Implications }\end{array}$ & N/A \\
\hline [41] & Agricultural Waste & $\begin{array}{l}\text { To transparently provide incentives to the farmers against agricultural } \\
\text { waste in waste-to-energy project }\end{array}$ & $\begin{array}{l}\text { Waste to Energy, } \\
\text { Auditability }\end{array}$ & Rewards \\
\hline [40] & Domestic Waste & $\begin{array}{l}\text { To efficiently manage and monitor smart garbage through a blockchain- } \\
\text { based system }\end{array}$ & $\begin{array}{l}\text { Waste Frauds, } \\
\text { Smart Bins Monitoring }\end{array}$ & Penalties \\
\hline [42] & Solid Waste & $\begin{array}{l}\text { To develop an Ethereum-based system to securely transfer tokens } \\
\text { to users as a reward for participating in waste management activities }\end{array}$ & $\begin{array}{l}\text { Waste Sorting, } \\
\text { Transparency }\end{array}$ & Rewards \\
\hline [37] & Electronic Waste & $\begin{array}{l}\text { To implement a blockchain-based system that can trace the assets } \\
\text { throughout their life cycle }\end{array}$ & Smartphone Tracking & Rewards \\
\hline [45] & General Waste & $\begin{array}{l}\text { To highlight the processes/participants involved in waste management } \\
\text { activities using a blockchain based system }\end{array}$ & $\begin{array}{l}\text { Waste Documentation, } \\
\text { Waste Shipment Tracking }\end{array}$ & N/A \\
\hline [65] & Industrial Waste & $\begin{array}{l}\text { To present a conceptual architecture of a system employing blockchain } \\
\text { technology for the industrial wastewater management }\end{array}$ & $\begin{array}{l}\text { Water Waste Monitoring, } \\
\text { Automation }\end{array}$ & N/A \\
\hline
\end{tabular}

supply chain operations [68-70]. The supply chain feature enables users to verify and trace the waste submitted by them. It can further assist in discovering the products manufactured by the waste submitted by the citizens.

\section{B. Swachcoin}

Swachcoin has leveraged multiple cutting-edge technologies to effectively manage residuals and industrial waste for converting it into useful products. Like Recerreum, it has implemented Ethereum-based smart contracts to calculate and transfer incentives to citizens for channelizing their waste. The key modules of the Swachcoin system include Swachh Adaptive Intelligence (SwATEL), Swachh Internet of Things (SwIOT), Swachh Bins (SwBIN), Swachh Big Data (SwATA), and Swachh Decentralised Application (SwAPP) [71, 72]. Among others, SwATEL is responsible for making the waste management equipment intelligent to increase their operational efficiency, thereby increasing the system productivity. The SwBIN module is capable of automatically segregate the waste based on its type, color, and dimension. The SwIOT enables to remotely control and manage the waste bins. The SwATA module is responsible for analyzing the waste management data to optimize routes of trucks to minimize fuel consumption rates. The SwAPP refers to an interface that offers unique features to the users such as user wallet, token credit system, truck location tracking, SwBIN waste level status, and unique user identification. Swachcoin offers both token-based and flatbased means to present incentives to the users for channelizing their waste properly. The blockchain part of Swachcoin records the transaction data on the public Ethereum platform. It also stores other data such as machine logs and prescriptive analytic reports on the blockchain for easy auditing and high transparency [71, 73].

\section{Plastic Bank}

Plastic Bank is a multi-technology-based project run by a Canada-based company. It has recently established several waste collection centers in the Philippines, Haiti, and Indonesia. It aims to enable waste collectors to sell the collected waste at a locally designated center at a competent rate [74, 75]. It offers incentives to the waste collectors as a reward for cleaning the ocean based on the type and weight of the waste collected. Subsequently, it sells the recycled waste to the manufacturers to manufacture new products. The role of blockchain technology in Plastic Bank is to register entities and immutability record each recycling activity for making the waste recycling process highly secure, trusted, auditable, and transparent. The plastic bank has considered IBM's blockchain platform, known as Hyperledger Fabric, that is hosted on a private network which is managed by the cognition foundry [76-78]. Blockchain technology assists automate the transfer of the cryptocurrency tokens to the wallet of the recyclers following successful recycling. The payments to the recyclers can be tracked, hence blockchain can eliminate the risk of data loss or theft. It also allows exchanging cryptocurrency tokens against the local currency. The registered organizations on this network can use the earned cryptocurrency tokens to pay tuition fees, get medical insurance, and pay basic utilities. It has provided a smartphone-based application that is linked to the blockchain-based wallet, and it assists the recyclers or waste collectors in managing their cryptocurrencies [74-77].

\section{RecycleGo and Empower}

RecycleGO has collaborated with DeepDive technologies group to bring about trust in the supply chain business of recycling materials. It has employed a Hyperledger Fabric platform to verify, track, trace, and report activities in recycling 
supply chain businesses. It connects the participants such as buyers, suppliers, shippers, recyclers, and other supply chain actors to the recycling services using smart contracts deployed on blockchain to increase the visibility for better decision making. It can assist to track the plastic bottles throughout their lifetime; from its manufacturing to collection and conversion back to the raw material for manufacturing new products. Apart from the supply chain operations, it also assists the haulers of recyclables to follow the optimal route as they are integrated with fleet management and route optimization system. The key hauling services offered by RecyleGo include routing efficiency, dispatch messaging service, containers' location tracking, and instant pickup confirmation service [7981]. Empower is a Plastic Bank-type blockchain-based startup that allows citizens to sell plastic waste in exchange for tokens ( $1 \mathrm{~kg}$ plastic waste = $1 \mathrm{EMP})$; the earned tokens are securely awarded and can be exchanged against the money or used to pay for waste clean up in other locations. Empower aims to develop a global waste deposit and tracking System that should allow the users to trace and track waste in a transparent way. It aims to use the Zafeplace blockchain platform to trace and track the end-of-life of the plastics [78, 82-84].

\section{E. Troventum and Agora Tech Lab (ATL) Project}

Troventum is a sustainable development digital project that aims to interconnect every participant of the waste supply chain through a trusted and decentralized platform. It facilitates the waste management participants such as producers, procurers, recyclers, product manufacturers, shippers, and retailers to perform their business activities in a secure, trusted, and auditable way. Troventum consists of several modules and has been implemented on the Ethereum blockchain platform. The users are offered cryptocurrency tokens as a reward for engaging in waste collection, sorting, and channelization. Troventum OS module of Troventum refers to a suite of software that offers bonuses to the people collecting and selling the domestic waste. The Recycler OS module enables waste recyclers to keep an immutable record of transactions related to receiving and recycling various types of waste. The Troventum. Coin module allows the product manufacturer to buy raw materials generated from the recycled waste from the suppliers/recyclers. Troventum. Trad streamlines the raw material shipment process between the raw material suppliers and product manufacturer [78, 85, 86]. Agora Tech Lab (ATL) aims to leverage a customized blockchain platform to securely transfer tokens as a reward to encourage the citizens to keep the environment pollution-free by channelizing their waste. ATL is a Rotterdam-based organization that integrates waste management systems to the blockchain platform to immutably store the waste management-related transactions on it. The tokens received by the waste collectors can be used for personal government services [78].

\section{Open Research Challenges}

In this section, we discuss several open research challenges that hinder the successful adoption of blockchain technology into smart cities for waste management.

\section{A. Smart Contracts Security}

The blockchain-based systems leveraged to manage waste in smart cities employ smart contracts to execute events and functions. Examples of such smart contracts include IoT-based waste bins monitoring, real-time waste shipment tracking, waste fraud detection, and stopping the illegal waste landfills. Solidity language is used to develop Ethereum smart contracts for waste management in smart cities. Being just another version of the software that runs on a distributed and permissionless network, the Ethereum smart contracts are prone to several security issues. Smart contracts are immutably stored on the blockchain that presents various pros and cons. For instance, smart contracts are safe against any modification by hackers; but, they cannot be modified by the developers to meet the new business requirements after their deployment. The hackers attempt to manipulate the execution of the smart contracts using loopholes present in smart contracts to execute it in favor of their activities (e.g., stealing the virtual currencies) [65, 87, 88]. The common vulnerabilities in smart contacts that are often exploited by hackers include reentrance attack, integer overflow, denial of service attacks, and remote code execution. Hence, it is very important to rigorously test the smart contracts before their deployment using highly proficient security analysis tools such as Smartcheck, ReGuard, OYENTE, Mythril, Securify, GASPER, to name a few $[65,87]$.

\section{B. Storage}

The business processes involved in waste monitoring, collection, segregation, transportation, and disposal generate the large amount of data. Such data could be in various forms such as videos, images, or documents that assure the waste management activities complies with local and global environmental protection and human safety laws. The examples of gathered data include the type of waste collected, realtime location of the shipped waste, recycling/landfill sites, and transportation route followed by waste transporting trucks [64]. Such data comes from several hundred thousand sensors deployed in smart cities to monitor the waste continuously, and storing it on the blockchain. Every node in the blockchain network stores a copy of this data, thus it leads to a shortage of blockchain storage capacity. The performance of blockchain technology is high when it stores and processes data of smallscale businesses. However, the performance of blockchain is severely affected by large-scale business applications. The decentralized storage systems such as IPFS, Filecoin, and Storj.Io store large-sized waste-related data in an efficient way $[87,89]$. The integration of blockchain with such systems can overcome the limitations of blockchain technology. A decentralized storage system (e.g., IPFS) generates an irreversible hash of the stored data. Such hashes can be immutably recorded on the blockchain to assure that data stored on the decentralized storage system has not been modified [47]. Also, blockchain-based systems can limit the size of data stored on blockchain by leveraging off-chain communication channels. 


\section{Scalability}

The stakeholders involved in the waste management process in smart cities require high quality of services (QoS) while using blockchain-based platforms. Among many other metrics, transaction throughput, the latency of the transaction's execution, and transactions cost highly impact the QoS of a blockchain platform. Considering the decentralized and selfgoverning blockchain technology, it is difficult to improve such parameters while ensuring high transaction execution transparency, security, and privacy. Bitcoin platform's throughput is up to seven transactions per second. It has been reported in various studies that the throughput of the Ethereum 1.0 platform is 16 to 20 transactions per second; whereas, Ethereum 2.0 promises a throughput of 100,000 transactions per second $[34,47,90]$. The existing solutions proposed to handle blockchain scalability issues are mainly classified into two layers. The layer 1 solutions concentrate on improving the onchain blockchain features such as consensus algorithm, block size, and structure of the ledger. However, each solution has its associated problems. For instance, the approach extending a block size can maximize the system throughput; but, it extends block propagation time. The extended blockchain propagation time can cause multiple blockchain forks. On the other hand, the layer 2 solutions have focused on shifting the complex operations to off-chain, thereby minimizing the burden on onchain blockchain resources to improve its throughput [91]. Among many solutions, Bitcoin-cashing, block compressing, lightweight and fast consensus algorithms, and sharding have focused on maximizing the throughput of the blockchain-based systems. Side-chain and cross-chain approaches are some examples of the layer-2 solutions that can assist in maximizing the throughput of the existing platforms [23, 34, 90, 91].

\section{Platform Interoperability Support}

Generally, the stakeholders (i.e., waste generators, collectors, shippers, and recyclers) involved in the waste management of smart cities have competing interests among themselves, and they belong to different organizations. Further, such organizations could have deployed heterogeneous blockchain platforms to perform their business activities. The high coordination and communication among the participating stakeholders require a smooth, timely, and fast execution of transactions related to waste management. The interoperability feature enables organizations that use heterogeneous blockchain platforms to interact and share data among themselves uninterruptedly, seamlessly, securely, and efficiently without any intervention by the end-users. Hence, despite the diversity in the supported language, interfaces, consensus protocols, and hashing algorithms, blockchain platforms implement technical and semantic interoperability to allow the participating stakeholders to perform cross-chain transactions [47, 92]. For instance, atomic swaps allow trustful cryptocurrency exchange by enabling the waste-handling players to transfer certain tokens from the Bitcoin platform to the Ethereum platform. Komodo's BarterDex tool has used atomic swaps to exchange cryptocurrencies in a decentralized network [93]. The approach mentioned in PolkaDot has implemented a designated blockchain platform that can work as a relay node to provide blockchain interoperability support [92]. One of the key requirements of the stakeholders involved in waste management activities is the security and privacy of data and transactions when interacting with another platform's user. Hence, future interoperability-supported blockchain platforms should be highly secure, fast, and privacy-preserving to meet the requirements of involved stakeholders.

\section{E. Privacy and Anonymity}

Guaranteeing data privacy and entity anonymity by the underlying blockchain-based platforms are the key requirements of stakeholders managing waste in smart cities. By design, blockchain is a distributed database that manages the data and transactions related to waste management in smart cities into a hierarchical chain of blocks. The security of waste management-related data and transactions is assured through cryptography hash functions and decentralized consensus protocols. The key features of existing blockchain platforms preserving the security and privacy of data include integrity, confidentiality, and anonymity of users' identity through digital signatures, system, data, and transactions availability through decentralization, and unlinkability of transactions to calculate the true identity of a user [14, 34, 94]. Ethereum provides the pseudonymous identity of the users as it presents a disguised identity for the user to preserve data privacy. The blockchain platforms leverage the hash of the user's public key to enable users to interact with the system. The use of such identifiers hides the identities of the users. However, successful inference attacks on the blockchain can create the linkage among a user's transactions to reveal the identities of users. More specifically, the public blockchain platforms are vulnerable to inference attacks as transactions, pseudonymous addresses, and other user data are publicly available. Private blockchain platforms run in a controlled environment, thus they are more secure than public blockchain platforms. Private blockchain platforms such as Hyperledger Fabric and Hyperledger Besu [22, 88] can preserve the privacy of waste management data through private channels and Orion private transactions manager, respectively.

\section{F. Slow Adoption}

The sensing and data transmission capabilities of IoT-based sensors have enabled officials to closely monitor the waste bins' status. Such data is useful to optimize routes of trucks shipping the waste to recycling centers. Blockchain technology has shown a great role to bring trust, security, fairness, operational transparency, and audit features to existing affairs of waste management handling in smart cities. It can assist the authorities to verify that the hazardous waste is properly disinfected before it is disposed of at a recycling center to minimize the chances of disease spreading[30, 38, 56]. The disposed of material at the recycling center can be sold to the manufacturers to manufacture new products. Thus, the increase in the rate of waste recycling can effectively strengthen the circular economy of waste material. Despite the many advantages of blockchain technology and the availability of several open-source projects for waste management as highlighted in 
Section III, blockchain adoption into the waste management industry is in its infancy. Several technological, institutional, and organizational factors can influence the adoption of blockchain in the waste management industry. The availability of a specific blockchain tool that can fully digitize the services of the waste management industry can influences its adoption [7, 8]. Also, the infrastructural facility that details various facilities such as waste transportation network, traffic control and management, fine-grained and transparent incentives and penalties models, and real-time waste monitoring are required for the successful adoption of the blockchain platform into the waste management industry. Currently, laws and regulations for blockchain are not mature enough, thereby affecting its adaptability in the waste management industry. Finally, organizational factors such as training facilities, top management support, perceived cost of investment, and available human resources greatly influence the adoption of blockchain into waste management within smart cities $[7,51,88]$.

\section{Concluding Remarks And ReCOMmendations}

In this paper, we have discussed how blockchain technology can be leveraged for managing waste within smart cities in a manner that is decentralized, tamper-proof, transparent, traceable and trackable, auditable, secure, and trustworthy. We explored the key opportunities offered by blockchain technology for managing various activities and actions related to the collection, shipment, segregation, disposal, and recycling of the waste in smart cities. We presented a blockchainbased framework for waste management to highlight system components, participants along with their role definition, and data flow among system components. We provided insightful discussions on the recent blockchain-based research projects and case studies to highlight the practicability of blockchain in the waste management of smart cities. We identified and discussed several challenges remaining to be addressed to unlock the full potential of blockchain in terms of waste management within smart cities. Our concluding remarks along with key recommendations include:

- The transparency and immutability features of blockchain can assist in tracing and tracking the amount and type of waste collected in a community, the details about waste collectors, the location from where it was collected, and the current shipment location and final destination of the collected waste.

- The fault tolerance and data tamper-proofing properties enable blockchain to efficiently manage scarce waste management resources, identify frauds related to illegal waste disposal and landfilling, and issue penalties to an individual/industry involved in hazardous waste spreading.

- The parameters such as system throughput, transaction execution latency, data volume, competing interests of the concerned participants, bugs and vulnerabilities in smart contracts, and available gas and size of the block can significantly affect the performance of blockchain-based solutions developed to manage waste.

- Segregating waste within smart cities through highly autonomous robots can assist in minimizing human inter- ference for health safety purposes. Blockchain technology can enable such robots to make effective decisions based on highly trusted, secure, transparent, and verifiable data.

- Employing a public blockchain platform for digitizing waste management services in smart cities faces many challenges related to preserving data and transaction privacy. Ensuring compliance with General data protection regulation laws for data privacy can increase the adaptability of public blockchain platforms in smart cities.

- In the future, we aim to propose and implement a Hyperledger Fabric-based system that will calculate the reputation of each registered waste recycling unit based on its environmentally friendly waste disposal policies.

\section{ACKNOWLEDGMENT}

This publication is based upon work supported by the Khalifa University of Science and Technology under Awards No. CIRA-2019-001 and RCII-2019-002, Center for Digital Supply Chain and Operations Management.

\section{REFERENCES}

[1] S. Kaza, L. Yao, P. Bhada-Tata, and F. Van Woerden, What a waste 2.0: A global snapshot of solid waste management to 2050. World Bank Publications, 2018.

[2] P. Bocquier, "World urbanization prospects: an alternative to the un model of projection compatible with the mobility transition theory," Demographic Research, vol. 12, pp. 197-236, 2005.

[3] G. K. Shyam, S. S. Manvi, and P. Bharti, "Smart waste management using internet-of-things (IoT)," in 2nd international conference on computing and communications technologies (ICCCT). IEEE, Chennai, India, 2017, pp. 199-203.

[4] D. Misra, G. Das, T. Chakrabortty, and D. Das, "An IoTbased waste management system monitored by cloud," Journal of Material Cycles and Waste Management, vol. 20, no. 3, pp. 1574-1582, 2018.

[5] B. Bhushan, A. Khamparia, K. M. Sagayam, S. K. Sharma, M. A. Ahad, and N. C. Debnath, "Blockchain for smart cities: A review of architectures, integration trends and future research directions," Sustainable Cities and Society, vol. 61, p. 102360, 2020.

[6] S. Singh, P. K. Sharma, B. Yoon, M. Shojafar, G. H. Cho, and I.-H. Ra, "Convergence of blockchain and artificial intelligence in IoT network for the sustainable smart city," Sustainable Cities and Society, vol. 63, p. 102364, 2020.

[7] I. J. Orji, S. Kusi-Sarpong, S. Huang, and D. VazquezBrust, "Evaluating the factors that influence blockchain adoption in the freight logistics industry," Transportation Research Part E: Logistics and Transportation Review, vol. 141, p. 102025, 2020.

[8] J. Angelis and E. R. da Silva, "Blockchain adoption: A value driver perspective," Business Horizons, vol. 62, no. 3, pp. 307-314, 2019.

[9] E. Ismagilova, L. Hughes, Y. K. Dwivedi, and K. R. Raman, "Smart cities: Advances in research—an infor- 
mation systems perspective," International Journal of Information Management, vol. 47, pp. 88-100, 2019.

[10] M. Poongodi, M. Hamdi, V. Vijayakumar, B. S. Rawal, and M. Maode, "An effective electronic waste management solution based on blockchain smart contract in 5 G communities," in 2020 IEEE 3rd 5G World Forum (5GWF). IEEE, 2020, pp. 1-6.

[11] C. Tao and L. Xiang, "Municipal solid waste recycle management information platform based on internet of things technology," in International Conference on Multimedia Information Networking and Security. IEEE, Nanjing, Jiangsu, China, 2010, pp. 729-732.

[12] S. Aleyadeh and A.-E. M. Taha, "An IoT-based architecture for waste management," in International Conference on Communications Workshops (ICC Workshops). IEEE, Kansas City, MO, USA, 2018, pp. 1-4.

[13] Y. He, H. Li, X. Cheng, Y. Liu, C. Yang, and L. Sun, "A blockchain based truthful incentive mechanism for distributed p2p applications," IEEE Access, vol. 6, pp. 27 324-27 335, 2018.

[14] G. G. Dagher, J. Mohler, M. Milojkovic, and P. B. Marella, "Ancile: Privacy-preserving framework for access control and interoperability of electronic health records using blockchain technology," Sustainable cities and society, vol. 39, pp. 283-297, 2018.

[15] L. Bach, B. Mihaljevic, and M. Zagar, "Comparative analysis of blockchain consensus algorithms," in 2018 41 st International Convention on Information and Communication Technology, Electronics and Microelectronics (MIPRO). IEEE, 2018, pp. 1545-1550.

[16] W. Ren, J. Hu, T. Zhu, Y. Ren, and K.-K. R. Choo, "A flexible method to defend against computationally resourceful miners in blockchain proof of work," Information Sciences, vol. 507, pp. 161-171, 2020.

[17] O. Vashchuk and R. Shuwar, "Pros and cons of consensus algorithm proof of stake. difference in the network safety in proof of work and proof of stake," Electronics and Information Technologies, vol. 9, no. 9, pp. 106-112, 2018.

[18] P. K. Singh, R. Singh, S. K. Nandi, and S. Nandi, "Managing smart home appliances with proof of authority and blockchain," in International Conference on Innovations for Community Services. Springer, 2019, pp. 221-232.

[19] R. Andreev, P. Andreeva, L. Krotov, and E. Krotova, "Review of blockchain technology: Types of blockchain and their application," Intellekt. Sist. Proizv., vol. 16, no. 1, pp. 11-14, 2018.

[20] D. Vujičić, D. Jagodić, and S. Ranić, "Blockchain technology, bitcoin, and ethereum: A brief overview," in 2018 17th international symposium infoteh-jahorina (infoteh). IEEE, 2018, pp. 1-6.

[21] A. Baliga, I. Subhod, P. Kamat, and S. Chatterjee, "Performance evaluation of the quorum blockchain platform," arXiv preprint arXiv:1809.03421, 2018.

[22] C. Cachin et al., "Architecture of the hyperledger blockchain fabric," in Workshop on distributed cryptocurrencies and consensus ledgers, vol. 310, no. 4. Chicago, IL, 2016.
[23] J. Xie, H. Tang, T. Huang, F. R. Yu, R. Xie, J. Liu, and Y. Liu, "A survey of blockchain technology applied to smart cities: Research issues and challenges," IEEE Communications Surveys \& Tutorials, vol. 21, no. 3, pp. 2794-2830, 2019.

[24] M. Moniruzzaman, S. Khezr, A. Yassine, and R. Benlamri, "Blockchain for smart homes: Review of current trends and research challenges," Computers \& Electrical Engineering, vol. 83, p. 106585, 2020.

[25] S. Hakak, W. Z. Khan, G. A. Gilkar, M. Imran, and N. Guizani, "Securing smart cities through blockchain technology: Architecture, requirements, and challenges," IEEE Network, vol. 34, no. 1, pp. 8-14, 2020.

[26] A. G. Ghandour, M. Elhoseny, and A. E. Hassanien, "Blockchains for smart cities: a survey," in Security in Smart Cities: Models, Applications, and Challenges. Springer, 2019, pp. 193-210.

[27] S. Aggarwal, R. Chaudhary, G. S. Aujla, N. Kumar, K.-K. R. Choo, and A. Y. Zomaya, "Blockchain for smart communities: Applications, challenges and opportunities," Journal of Network and Computer Applications, vol. 144, pp. 13-48, 2019.

[28] M. D. LaGrega, P. L. Buckingham, and J. C. Evans, Hazardous waste management. Waveland Press, 2010.

[29] M. Kouhizadeh and J. Sarkis, "Blockchain practices, potentials, and perspectives in greening supply chains," Sustainability, vol. 10, no. 10, p. 3652, 2018.

[30] Z. Mingaleva, N. Vukovic, I. Volkova, and T. Salimova, "Waste management in green and smart cities: A case study of Russia," Sustainability, vol. 12, no. 1, p. 94, 2020.

[31] Olivia Staub, "Revolutionizing the waste supply chain: Blockchain for social good," online, accessed 1/22/2021, August 2019, https://www.ibm.com/blogs/blockchain/2019/08/.

[32] K. Salah, A. Alfalasi, M. Alfalasi, M. Alharmoudi, M. Alzaabi, A. Alzyeodi, and R. Ahmad, "IoT-enabled shipping container with environmental monitoring and location tracking," in IEEE 17th Annual Consumer Communications \& Networking Conference (CCNC). IEEE, 2020, pp. 1-6.

[33] S. Saberi, M. Kouhizadeh, J. Sarkis, and L. Shen, "Blockchain technology and its relationships to sustainable supply chain management," International Journal of Production Research, vol. 57, no. 7, pp. 2117-2135, 2019.

[34] R. W. Ahmad, K. Salah, R. Jayaraman, I. Yaqoob, M. Omar, and S. Ellahham, "Blockchain-based Forward Supply Chain and Waste Management for COVID-19 Medical Equipment and Supplies," 1 2021. [Online]. Available: 10.36227/techrxiv.13553942.v1

[35] P. K. Gopalakrishnan, J. Hall, and S. Behdad, "Cost analysis and optimization of blockchain-based solid waste management traceability system," Waste Management, vol. 120, pp. 594-607, 2020.

[36] CPCB, "Guidelines on implementation of E-Waste (Management) Rules, 2016," online, accessed 1/19/2021, January 2016, 
http://www.indiaenvironmentportal.org.in/content/436611/.

[37] T. K. Dasaklis, F. Casino, and C. Patsais, "A traceability and auditing framework for electronic equipment reverse logistics based on blockchain: The case of mobile phones," arXiv preprint arXiv:2005.11556, 2020.

[38] N. Gupta and P. Bedi, "E-waste management using blockchain based smart contracts," in International Conference on Advances in Computing, Communications and Informatics (ICACCI). IEEE, 2018, pp. 915-921.

[39] Naveen Joshi, "Revolutionizing waste management with blockchain technology," online, accessed 1/24/2021, April 2020, https://www.allerin.com/blog/revolutionizing-wastemanagement-with-blockchain-technology.

[40] O. Akter, "Blockchain leveraged incentive providing waste management system," 042020.

[41] D. Zhang, "Application of blockchain technology in incentivizing efficient use of rural wastes: A case study on Yitong system," Energy Procedia, vol. 158, pp. 67076714, 2019.

[42] A. França, J. A. Neto, R. Gonçalves, and C. Almeida, "Proposing the use of blockchain to improve the solid waste management in small municipalities," Journal of Cleaner Production, vol. 244, p. 118529, 2020.

[43] Y.-C. Jang, C. Lee, O.-S. Yoon, and H. Kim, "Medical waste management in Korea," Journal of environmental management, vol. 80, no. 2, pp. 107-115, 2006.

[44] A. Galierikova and J. Sosedova, "Intermodal transportation of dangerous goods," NAŠE MORE: znanstvenostručni časopis za more $i$ pomorstvo, vol. 65 , no. 3 Supplement, pp. 8-11, 2018.

[45] G. Ongena, K. Smit, J. Boksebeld, G. Adams, Y. Roelofs, and P. Ravesteyn, "Blockchain-based smart contracts in waste management: a silver bullet?" in Bled eConference, 2018, p. 19.

[46] Y. Chen, H. Li, K. Li, and J. Zhang, "An improved P2P file system scheme based on IPFS and blockchain," in IEEE International Conference on Big Data (Big Data). IEEE, 2017, pp. 2652-2657.

[47] R. W. Ahmad, H. Hasan, I. Yaqoob, K. Salah, R. Jayaraman, and M. Omar, "Blockchain for aerospace and defense: Opportunities and open research challenges," Computers \& Industrial Engineering, p. 106982, 2020.

[48] S. Mirchandani, S. Wadhwa, P. Wadhwa, and R. Joseph, "IoT enabled dustbins," in International conference on big data, IoT and data science (BID). IEEE, 2017, pp. 73-76.

[49] B. Esmaeilian, B. Wang, K. Lewis, F. Duarte, C. Ratti, and S. Behdad, "The future of waste management in smart and sustainable cities: A review and concept paper," Waste management, vol. 81, pp. 177-195, 2018.

[50] Mitashi Singh, "Waste Management Rules, Compliances and Associated Methodologies," online, accessed 1/22/2021, January 2016, https://www.cseindia.org/waste-management-rulescompliances-and-associated-methodologies-8703.

[51] R. W. Ahmad, K. Salah, R. Jayaraman, I. Yaqoob, S. Ellahham, and M. Omar, "Blockchain and COVID-
19 pandemic: Applications and challenges," 2020.

[52] M. Mohan, R. Chetty, V. Sriram, M. Azeem, P. Vishal, and G. Pranav, "IoT enabled smart waste bin with real time monitoring for efficient waste management in metropolitan cities," International Journal of Advanced Science and Convergence, vol. 1, no. 3, pp. 13-19, 2019.

[53] M.-V. Bueno-Delgado, J.-L. Romero-Gázquez, P. Jiménez, and P. Pavón-Mariño, "Optimal path planning for selective waste collection in smart cities," Sensors, vol. 19, no. 9, p. 1973, 2019.

[54] T. Ali, M. Irfan, A. S. Alwadie, and A. Glowacz, "IoTbased smart waste bin monitoring and municipal solid waste management system for smart cities," Arabian Journal for Science and Engineering, vol. 45, pp. $10185-$ $10198,2020$.

[55] N. P. S. S. P. K. Murlidhar Gangwani, Madhuresh Pandey, "A comprehensive study on waste segregation techniques," International Journal of Engineering Research \& Technology (IJERT), vol. 08, pp. 10 185-10 198, 2019.

[56] I. Ilankoon, Y. Ghorbani, M. N. Chong, G. Herath, T. Moyo, and J. Petersen, "E-waste in the international context: A review of trade flows, regulations, hazards, waste management strategies and technologies for value recovery," Waste Management, vol. 82, pp. 258-275, 2018.

[57] S. Nandhini, S. S. Mrinal, N. Balachandran, K. Suryanarayana, and D. H. Ram, "Electronically assisted automatic waste segregation," in 3rd International Conference on Trends in Electronics and Informatics (ICOEI). IEEE, 2019, pp. 846-850.

[58] B. M. Chinnathurai, R. Sivakumar, S. Sadagopan, and J. M. Conrad, "Design and implementation of a semiautonomous waste segregation robot," in SoutheastCon 2016. IEEE, 2016, pp. 1-6.

[59] C. Boanta, M. Margaritescu, A. Verl, and C. Brisan, "Design concept of an automated solid waste selection system," in ISR 2018; 50th International Symposium on Robotics. VDE, 2018, pp. 1-4.

[60] A. Chidepatil, P. Bindra, D. Kulkarni, M. Qazi, M. Kshirsagar, and K. Sankaran, "From trash to cash: How blockchain and multi-sensor-driven artificial intelligence can transform circular economy of plastic waste?" Administrative Sciences, vol. 10, no. 2, p. 23, 2020.

[61] E. C. Ferrer, "The blockchain: A new framework for robotic swarm systems," in Proceedings of the future technologies conference. Springer, 2018, pp. 10371058.

[62] Edin Golubovic, "Improved Smart Waste Management for Smart City," online, accessed 1/28/2021, February 2018 , https://medium.com/inovatink/improved-smartwaste-management-for-smart-city-7387a11f6204.

[63] M. Arebey, M. Hannan, H. Basri, and H. Abdullah, "Solid waste monitoring and management using RFID, GIS, and GSM," in IEEE Student Conference on Research and Development (SCOReD). IEEE, 2009, pp. 37-40.

[64] D. Schmelz, K. Pinter, S. Strobl, L. Zhu, P. Niemeier, and T. Grechenig, "Technical mechanics of a trans- 
border waste flow tracking solution based on blockchain technology," in IEEE 35th International Conference on Data Engineering Workshops (ICDEW). IEEE, 2019, pp. 31-36.

[65] S. Hakak, W. Z. Khan, G. A. Gilkar, N. Haider, M. Imran, and M. S. Alkatheiri, "Industrial wastewater management using blockchain technology: Architecture, requirements, and future directions," IEEE Internet of Things Magazine, vol. 3, no. 2, pp. 38-43, 2020.

[66] M. R. Laouar, Z. T. Hamad, and S. Eom, "Towards blockchain-based urban planning: Application for waste collection management," in Proceedings of the 9th International Conference on Information Systems and Technologies, 2019, pp. 1-6.

[67] A. Zhang, R. Y. Zhong, M. Farooque, K. Kang, and V. Venkatesh, "Blockchain-based life cycle assessment: An implementation framework and system architecture," Resources, Conservation and Recycling, vol. 152, p. 104512, 2020.

[68] Bohdan Yakubovych, "Recereum," online, accessed 2/7/2021, February 2017, https://recereum.com/.

[69] R. Sham, A. A. A. Hussin, N. Abdamia, S. Mohamed, O. Musa, and R. Z. Rasi, "Blockchain technology application in a refuse management system," in 2nd International Conference on Computer and Information Sciences (ICCIS). IEEE, 2020, pp. 1-5.

[70] "Recereum," White Paper [online] https://recereum.com/, UKR TRANS EXPRESS, May 2017.

[71] "Swachhcoin," White Paper [online] http://swachhcoin.com/, Swachhcoin foundation, May 2018.

[72] Serkan Dereli, "Industrial Waste Problem Solution with SWACHHCOIN," online, accessed 2/7/2021, june 2019, https://hive.blog/bitcoin/@serkandereli27/swachhcoinile-enduestriyel-atik-sorunu-coezuemue.

[73] Andreea Hodicsek, "Swachhcoin - Decentralising Waste Management," online, accessed 2/7/2021, August 2018, https://coininfo.news/swachhcoin-decentralising-wastemanagement/.

[74] SC Johnson, "Plastic Bank use blockchain tokens to fight plastic pollution," online, accessed 2/9/2021, January 2020, https://www.ledgerinsights.com/sc-johnsonplastic-bank-blockchain-tokens-plastic-pollution/.

[75] Kimberley Mok, "Plastic Bank Using Blockchain Tech to Monetize Plastic Waste," online, accessed 2/9/2021, June 2018, https://thenewstack.io/plastic-bankusing-blockchain-tech-to-monetize-plastic-waste/.

[76] Andrew Singer, "Unwrapping the Ocean Plastic Conundrum Via Blockchain," online, accessed 2/9/2021, October 2019, https://cointelegraph.com/news/unwrappingthe-ocean-plastic-conundrum-via-blockchain.

[77] Michael Peshkam, "How Blockchain Can Win the War Against Plastic Waste," online, accessed 2/9/2021, July 2019, https://knowledge.insead.edu/blog/inseadblog/how-blockchain-can-win-the-war-against-plasticwaste-12006.

[78] Climate Kick, "Working paper on plastic waste recovery by regional blockchain networks," online, accessed
2/14/2021, February 2019, https://ecircular.climatekic.org/reports/working-paper-on-plastic-waste-recoveryby-regional-blockchain-networks/.

[79] RecyleGO, "Innovative Technologies: RecyleGO," online, accessed 2/9/2021, September 2018, https://www.recyclego.com/innovative-technologies/.

[80] Kirstin Linnenkoper, "Blockchain tracks entire life cycle of recycled materials," online, accessed 2/9/2021, September 2020, https://recyclinginternational.com/plastics/blockchaintracks-entire-life-cycle-of-recycled-materials/31517/.

[81] Trevor Clawson, "The Blockchain Startup That Plans To Save The World From Plastic Waste," online, accessed 2/9/2021, December 2018, https://www.forbes.com/sites/trevorclawson/2018/12/19/theblockchain-startup-that-plans-to-save-the-world-fromplastic-waste/?sh=54e005156987.

[82] Hazel Sheffield, "Norway's Empower is using blockchain to clean up the world's oceans," online, accessed 2/9/2021, October 2018, https://www.independent.co.uk/news/business/indyventure /plastic-waste-recycling-blockchain-empower-osloinnovation-a8565906.html.

[83] Wilhelm Myrer, "Winnovart Explore - introducing Empower Norway: Disrupting the plasticwaste ecosystem with blockchain technolog," online, accessed 2/9/2021, October 2019, https://www.winnovart.com/winnovart-exploreintroducing-empower-norway-disrupting-the-plasticwaste-ecosystem-with-blockchain-technology/.

[84] A. Böckel, A.-K. Nuzum, and I. Weissbrod, "Blockchain for the circular economy: Analysis of the researchpractice gap," Sustainable Production and Consumption, 2020.

[85] "Troventum: Recycling platform on blockchain," White Paper [online] https://troventum.com/, Troventum LTD, Malta, May 2019.

[86] Ivan Kalishevich, "Troventum is the future of recycling ," online, accessed 2/11/2021, May 2018, http://insnews.fi/en/100/?1s-art1=160.

[87] R. W. Ahmad, H. Hasan, R. Jayaraman, K. Salah, and M. Omar, "Blockchain applications and architectures for port operations and logistics management," Research in Transportation Business \& Management, p. 100620, 2021.

[88] R. W. Ahmad, K. Salah, R. Jayaraman, I. Yaqoob, S. Ellahham, and M. Omar, "The role of blockchain technology in telehealth and telemedicine," International Journal of Medical Informatics, p. 104399, 2021.

[89] N. Z. Benisi, M. Aminian, and B. Javadi, "Blockchainbased decentralized storage networks: A survey," Journal of Network and Computer Applications, p. 102656, 2020.

[90] A. Chauhan, O. P. Malviya, M. Verma, and T. S. Mor, "Blockchain and scalability," in IEEE International Conference on Software Quality, Reliability and Security Companion (QRS-C). IEEE, 2018, pp. 122-128.

[91] Q. Zhou, H. Huang, Z. Zheng, and J. Bian, "Solutions to scalability of blockchain: A survey," IEEE Access, vol. 8, 
pp. 16440-16455, 2020.

[92] "Polkadot," White Paper [online] https://polkadot.network/PolkaDotPaper, Ethereum Parity, May 2016.

[93] S. Schulte, M. Sigwart, P. Frauenthaler, and M. Borkowski, "Towards blockchain interoperability," in International Conference on Business Process Management. Springer, 2019, pp. 3-10.

[94] R. Zhang, R. Xue, and L. Liu, "Security and privacy on blockchain," ACM Computing Surveys (CSUR), vol. 52, no. 3, pp. 1-34, 2019. 